\title{
Dynasplint Trismus System exercises for trismus secondary to head and neck cancer: a prospective explorative study
}

\author{
Jolanda I. Kamstra ${ }^{1}$ - Harry Reintsema ${ }^{1}$ - Jan L. N. Roodenburg ${ }^{1}$ • Pieter U. Dijkstra ${ }^{1,2}$
}

Received: 22 December 2015 / Accepted: 9 February 2016 / Published online: 8 March 2016

(C) The Author(s) 2016. This article is published with open access at Springerlink.com

\begin{abstract}
Purpose The Dynasplint Trismus System (DTS) can be used to treat trismus secondary to head and neck cancer. We conducted a prospective study with the following aims: (1) to determine the effects of DTS exercises on changes in mouth opening, pain, mandibular function, quality of life $(\mathrm{QoL})$, and symptomatology and (2) to analyze the patients' perception on DTS exercises, including user satisfaction, experiences, comfort, and compliance.

Methods The patients were instructed to exercise with the DTS for at least 16 weeks. Changes in mouth opening, pain, mandibular function, QoL, and symptomatology were evaluated, as well as the patients' perception of DTS exercises.

Results Eighteen consecutive patients were included. Baseline mouth opening was $22.6 \mathrm{~mm}$ (sd 7.6). After the patients completed the DTS exercise program, mouth opening increased $(7.1 \mathrm{~mm}, \mathrm{sd} 4.7)$ and perceived difficulty of opening the mouth improved significantly $(p<0.05)$. No significant effects were found in mandibular function, QoL, and overall symptomatology. The patients' perception was diverse. They reported effectiveness and positive feelings of the results and would recommend DTS exercises to other patients. About half of them thought DTS exercises were burdensome.
\end{abstract}

Jolanda I. Kamstra

j.i.kamstra@umcg.nl

1 Department of Oral and Maxillofacial Surgery, University of Groningen, University Medical Center Groningen, PO Box 30.001, 9700 RB Groningen, the Netherlands

2 Center for Rehabilitation, Department of Rehabilitation Medicine, University of Groningen, University Medical Center Groningen, Groningen, the Netherlands
Conclusions Mouth opening increased significantly after the DTS exercise program, relative to baseline. About one third of the gained increase was lost in the follow-up period. In general, the patients were satisfied about the effects and the DTS exercise program.

Keywords Head and neck neoplasms · Trismus · Exercise therapy $\cdot$ Physical therapy modalities $\cdot$ Dynasplint Trismus System

\section{Introduction}

Many patients experience adverse effects following treatment of head and neck cancer. Trismus, a restricted mouth opening of $35 \mathrm{~mm}$ or less, is one of those adverse effects [1-4]. The prevalence is between 5 and $46 \%[2,4,5]$. Trismus has a negative influence on quality of life (QoL) and mandibular function (chewing, eating) [1, 6, 7]. It can impair speech, oral hygiene, dental treatment, nutrition, airway clearance, and oncological follow-up [7, 8]. Exercise therapy is used to treat trismus in head and neck cancer patients $[5,9]$. It appeared more effective if initiated soon after the treatment of the tumor [10]. Once trismus becomes established, only a limited increase in mouth opening can be achieved [11, 12].

Trismus can be treated with conventional exercises using simple tools such as tongue depressors, corkscrew devices, and rubber plugs. It can also be treated with advanced jaw stretching devices as the Dynasplint Trismus System $^{\mathbb{B}}$ (DTS). The DTS provides low-torque, prolonged-duration stretching with the aim of lengthening the affected connective tissue permanently. In an animal model, low-torque and prolonged-duration stretching was more effective for restoring range of motion than hightorque, short-duration stretching [13]. 
The effects of DTS exercises have been described in three retrospective studies. Increases of mouth opening from 6.2 to $13.6 \mathrm{~mm}$ were seen. None of these studies reported adverse events, and none reported on change in pain, mandibular function, QoL, or symptomatology [14-16]. Also, the patients' perception of DTS exercises is unknown.

We therefore conducted a prospective study with the following aims: (1) to determine the effects of DTS exercises on changes in mouth opening, pain, mandibular function, QoL, and symptomatology and (2) to analyze the patients' perception on DTS exercises, including user satisfaction, experiences, comfort, and compliance.

\section{Materials and methods}

\section{Study design and setting}

We performed an explorative prospective study with a prepost design, using mixed methods (quantitative and qualitative research). The study was conducted between November 2012 and February 2014 at the Department of Oral and Maxillofacial Surgery of the University Medical Center Groningen, the Netherlands. The study was approved by the Ethics Committee and was carried out according to the regulations of our institute. After being given a verbal and written explanation, the patients signed the informed consent form.

\section{Study population}

We included patients who were being treated for head and neck cancer (including surgery, radiotherapy, and chemotherapy) with trismus (mouth opening of $35 \mathrm{~mm}$ or less) and who wanted to increase their mouth opening. The exclusion criteria were 17 years or younger, osteoporosis, osteoradionecrosis, and inability to provide informed consent. Since this was an explorative study, no sample size calculation was performed.

\section{DTS exercise program}

The DTS exercise program consisted of three training sessions per day with session duration of $30 \mathrm{~min}$, with a gradual increase in time and stretching forces as tolerated. With this device, the stretching is performed passively. If the exercises were well tolerated, forces were increased every 2 weeks until maximum tolerance was reached.

Since the exercises are expected to be more effective if initiated soon after the treatment of the tumor, the patients were divided into two groups based on the interval (in months) between the primary tumor treatment and the start of the DTS exercise program [10]. If this interval was less than 36 months or was 36 months, patients were assigned to group $\leq 36$. If this interval was more than 36 months, patients were assigned to group $>36$. The two groups were prescribed a slightly different protocol. All the patients were instructed to perform the DTS exercises for at least 16 weeks [14-16]. For patients in group $\leq 36$, if additional gain in mouth opening was expected or if the patients wished to continue after the 16 weeks, then the period of DTS exercises was extended. Patients of group $>36$ were instructed to exercise for at least 16 weeks; they were instructed to continue exercising until no further gain in mouth opening was expected, up to a maximum of 28 weeks.

All the patients were asked to record their daily experiences. If mouth opening had increased above $35 \mathrm{~mm}$ and the DTS exercises went well, the patients were instructed to perform additional active lateral exercises. One follow-up appointment was planned 14 weeks after the end of the DTS exercise program. An overview of the procedures per week is included in Appendix 1.

The patients received no other concurrent exercise therapy during this study. If the patients were unable to perform DTS exercises, they were not included and offered a different type of exercise therapy.

\section{Data}

Data regarding tumor and treatment were extracted from the medical records.

\section{(1) Effects}

Outcome variables were mouth opening, pain, mandibular function, QoL, and symptomatology.

Mouth opening was measured in millimeters using an OraStretch $^{\circledR}$ Range-of-Motion Scale. The patients were asked to open their mouth as far as possible, and mouth opening was measured as the maximum interincisal distance. If the patients were edentulous and not wearing a dental prosthesis, mouth opening was measured from the alveolar ridge. Pain at rest and at maximum mouth opening was scored on a visual analog scale (VAS) with a score range of $0-100$. Mandibular function was assessed by means of the score on the Mandibular Function Impairment Questionnaire (MFIQ) with a score range of 0-68 [17]. Higher scores on the MFIQ indicate a more impaired mandibular function. QoL and symptomatology were assessed by means of the European Organization for Research and Treatment of Cancer (EORTC) Quality of Life Questionnaire C30 (QLQ-C30) and EORTC Quality of Life Questionnaire Head \& Neck 35 (QLQ-H\&N35) with a score range of $0-100$ [18-20]. A high score on the global health status or the symptom scale of the QLQ-C30 indicates a high QoL or a high level of symptoms, respectively. QLQ-H\&N35 scores for overall symptomatology of the head and neck area (questions 1 to 30 ) and perceived difficulty of opening the 
mouth as symptomatology for mouth opening (question 10) were used. A high score on the QLQ-H\&N35 indicates a high level of symptoms.

\section{(2) Patients' perception}

User satisfaction with the DTS was measured by the score on the D-QUEST 2.0 with a score range of 12-60. The DQUEST is a reliable and validated instrument to assess user satisfaction regarding assistive device provisions [21]. Higher scores indicate higher user satisfaction. Experiences, comfort, and compliance regarding DTS exercises were assessed with a semi-structured interview and were described qualitatively (Appendix 2). Interviews were recorded and transcribed verbatim.

\section{Statistics}

Pre- and post-DTS exercise program outcomes were analyzed with the Friedman test. Change of mouth opening was analyzed with the Wilcoxon test. Independent variables possibly related to change in mouth opening were analyzed for association using Spearman's correlation coefficient and the Mann-Whitney $U$ test. All analyses were performed with SPSS 22.0 for Windows software (SPSS Inc., Chicago, IL, USA).

\section{Results}

\section{Participants}

In total, 18 consecutive patients were included: 12 in group $\leq 36$ and six in group $>36$. Complete data to the end of the DTS exercise program was available for 15 patients. Half of the study population was male. Mean age was 62.1 (sd 12.7) years. Five patients had undergone a different exercise therapy for their trismus prior to enrolment in the DTS exercise program (Table 1).

One patient died as result of a cardiovascular incident (patient K). Two patients were unable to complete the DTS exercise program, one patient due to a decrease of mouth opening (patient Q) and one due to a locoregional recurrence of the tumor (patient R). Three patients could not be included for the analyses after completing the DTS exercise program: two patients had a locoregional recurrence and were not able to come to the follow-up appointment (patients $\mathrm{F}$ and $\mathrm{J}$ ), and one patient had to start with conventional exercises because of a rapid decrease in mouth opening (patient $\mathrm{C}$ ). Complete data up to follow-up was available for 12 patients. However, one of these patients quit exercising after 12 weeks because of pain (patient $\mathrm{N}$ ). The duration of the DTS exercise program was extended after the 16 weeks in one patient (patient $\mathrm{P}$ ).
Table 1 Patient, tumor, and treatment characteristics

\begin{tabular}{|c|c|}
\hline Variable & $N(\%)^{\mathrm{a}}$ \\
\hline \multicolumn{2}{|l|}{ Patient characteristics } \\
\hline Male & $9(50)$ \\
\hline Age at baseline (years), mean (sd) & $62.1(12.7)$ \\
\hline Deceased & $1(6)$ \\
\hline \multicolumn{2}{|l|}{ Dental state } \\
\hline Dentulous & $10(56)$ \\
\hline Partially edentulous & $4(22)$ \\
\hline Edentulous & $4(22)$ \\
\hline Previous exercise therapy & $5(28)$ \\
\hline $\begin{array}{l}\text { Interval between primary tumor treatment } \\
\text { and start of DTS exercise program } \\
\text { (months), median (IQR) }\end{array}$ & $18.4(12.4 ; 54.8)$ \\
\hline Group $\leq 36$, median (IQR) & $13.9(7.3-19.0)$ \\
\hline Group >36, median (IQR) & $110.3(44.1 ; 236.6)$ \\
\hline \multicolumn{2}{|l|}{ Tumor characteristics } \\
\hline Squamous cell carcinoma & $14(78)$ \\
\hline \multicolumn{2}{|l|}{ Location of the primary tumor ${ }^{\mathrm{b}}$} \\
\hline Oral cavity & $9(50)$ \\
\hline $\begin{array}{l}\text { Pharynx (oropharynx, nasopharynx, } \\
\text { hypopharynx) }\end{array}$ & $7(39)$ \\
\hline Maxillary sinus & $1(6)$ \\
\hline Skin (region ear) & $1(6)$ \\
\hline Stage T4 & $7(39)$ \\
\hline \multicolumn{2}{|l|}{ Treatment characteristics primary tumor ${ }^{\mathrm{c}}$} \\
\hline Photodynamic therapy & $1(6)$ \\
\hline Surgery & $11(61)$ \\
\hline Neck dissection & $10(56)$ \\
\hline Radiotherapy & $14(78)$ \\
\hline Dose radiation on primary tumor, mean (sd) & $65.3(5.1)$ \\
\hline Chemotherapy & $5(28)$ \\
\hline
\end{tabular}

$I Q R$ interquartile range

${ }^{\text {a }} N(\%)$ unless mentioned otherwise subsequent to the variable

${ }^{\mathrm{b}}$ Some patients underwent a combination of treatment modalities

${ }^{\mathrm{c}}$ Exceeds $100 \%$ due to rounding

\section{Outcome data}

(1) Effects

Mouth opening, pain, mandibular function, QoL, and symptomatology at the different time points are presented in Fig. 1 and Table 2. Mouth opening at baseline was $22.6 \mathrm{~mm}$ $(\mathrm{sd} 7.5)(n=18)$ and increased $7.1 \mathrm{~mm}(\mathrm{sd} 4.7)$ after the DTS exercise program in the total study population. Of the eight partially edentulous and edentulous patients, one patient was not wearing a dental prosthesis for the lower jaw, so mouth opening was measured from the alveolar ridge of the mandible. The increase in group $\leq 36$ was $7.3 \mathrm{~mm}$ (sd 4.7); in group $>36$, it was $6.5 \mathrm{~mm}$ (sd 5.3). The increase in mouth opening 


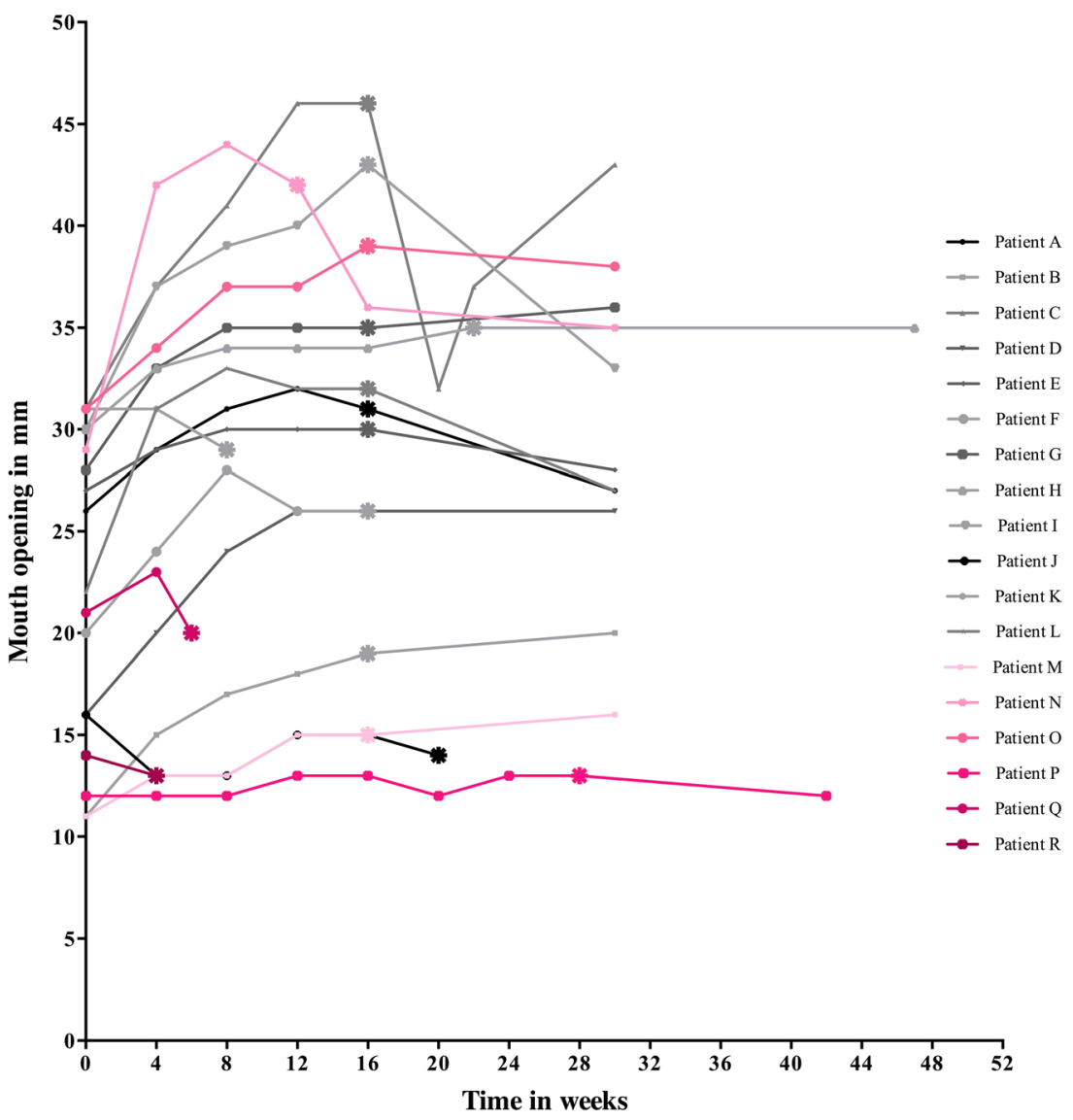

Fig. 1 Group $<36$ (patients $A$ until $L$, interval between primary tumor treatment and start of the DTS exercise program less than 36 months): gray shades. Group $>36$ (patients $M$ till $R$, interval between primary tumor treatment and start of the DTS exercise program more than 36 months): pink shades. Asterisk, end of the DTS exercise program

This interview was planned after the DTS exercise program, but the patient died. One patient was not interviewed because of logistic reasons.

The patients' experiences were diverse. Six patients stated that the DTS exercises were burdensome, especially towards the end of the 16 weeks. Four patients had previous experience with other stretching devices, and all preferred the DTS. All the patients reported an effect from the DTS exercise program. Nine patients stated that the effects were important for them. Four patients reported that the time required to do the DTS exercises was the only disadvantage, two patients reported pain during the DTS exercises, and five patients reported no disadvantage at all. All the patients reported positive feelings about the results and would recommend this type of exercise therapy to other patients. Two patients were instructed to perform active lateral exercises additionally; both found these exercises difficult to perform, and in their opinion, the device was not adequate for these exercises (Appendix 3).

Eight patients reported no discomfort during the DTS exercises. One patient had to use pain medication after the DTS exercises because of the pain experienced during the exercises. Ten patients reported that operating the device and adjusting the correct stretching forces were easy. Five patients 
Table 2 Mouth opening, pain, mandibular function, QoL, and symptomatology

\begin{tabular}{|c|c|c|c|c|c|c|}
\hline & $\begin{array}{l}\begin{array}{l}\text { Baseline } \\
(n=18)\end{array} \\
\text { Mean (sd) }\end{array}$ & $\begin{array}{l}\text { End of DTS } \\
\text { exercise program } \\
(n=15) \\
\text { Mean (sd) }\end{array}$ & 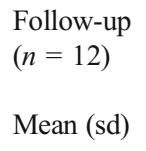 & $\begin{array}{l}\text { Significance } \\
\text { (Friedman) }\end{array}$ & $\begin{array}{l}\text { Baseline vs. end } \\
\text { of DTS exercise } \\
\text { program }(n=15) \\
\text { Mean (sd) }\end{array}$ & $\begin{array}{l}\text { Baseline vs. } \\
\text { follow-up } \\
(n=12) \\
\text { Mean (sd) }\end{array}$ \\
\hline Mouth opening $(\mathrm{mm})$ & $22.6(7.6)$ & $29.7(10.8)$ & $27.8(8.3)$ & $<0.001 *$ & $7.1(4.7)$ & $5.0(3.2)$ \\
\hline Group $\leq 36$ & $24.0(6.8)$ & $30.6(9.4)$ & $29.0(5.3)$ & $0.001 *$ & $7.3(4.7)$ & $5.3(3.5)$ \\
\hline Group $>36$ & $19.7(8.8)$ & $27.3(15.4)$ & $25.3(13.1)$ & 0.057 & $6.5(5.2)$ & $4.5(3.1)$ \\
\hline Pain at rest (VAS score $0-100$ points) & $1.7(5.0)$ & $2.3(6.7)$ & $5.2(11.1)$ & 0.584 & $0.9(8.5)$ & $3.5(12.1)$ \\
\hline $\begin{array}{l}\text { Pain at maximal mouth opening } \\
\text { (VAS score } 0-100 \text { points) }\end{array}$ & $21.8(19.3)$ & $11.9(13.8)$ & $24.8(21.9)$ & $0.042 *$ & $-6.1(15.5)$ & $3.1(15.5)$ \\
\hline MFIQ score (0-68 points) & $28.8(15.3)$ & $24.1(14.8)$ & $22.7(11.7)$ & 0.920 & $-2.8(13.3)$ & $-2.0(10.1)$ \\
\hline \multicolumn{7}{|l|}{$\begin{array}{l}\text { EORTC QLQ-C30 scores } \\
(0-100 \text { points })\end{array}$} \\
\hline Global health status (QoL) & $75.5(21.9)$ & $81.1(17.4)$ & $86.8(15.3)$ & 0.141 & $0.0(11.4)$ & $6.9(11.1)$ \\
\hline Symptomatology overall & $13.1(15.6)$ & $10.3(11.8)$ & $9.4(13.7)$ & 0.779 & $-0.7(10.8)$ & $0.4(11.9)$ \\
\hline \multicolumn{7}{|l|}{$\begin{array}{l}\text { EORTC QLQ-H\&N35 scores } \\
\text { (0-100 points })\end{array}$} \\
\hline Symptomatology overall & $22.9(15.8)$ & $17.5(13.4)$ & $13.1(9.6)$ & 0.086 & $-1.9(8.3)$ & $-5.4(9.1)$ \\
\hline $\begin{array}{l}\text { Perceived difficulty of opening } \\
\text { the mouth }\end{array}$ & 83.3 (20.6) & $60.0(31.4)$ & $58.3(32.2)$ & $0.006^{*}$ & $-20.0(24.6)$ & $-22.2(29.6)$ \\
\hline
\end{tabular}

*Significant $(p<0.05)$

stated that the prescribed stretching schedule of three times 30 min per day was optimal, while seven patients stated that 30 min of exercise per session is too long and suggested sessions between 10 and $20 \mathrm{~min}$.

Seven patients stated that they were motivated to exercise by the positive effects and four patients by self-discipline. Seven patients reported no difficulties in compliance with the DTS exercise program, and three patients reported difficulties with fitting the DTS exercises into their daily routine. Eight patients reported that they exercised according to the schedule the whole period; the other two patients reported that they exercised in the last weeks only a couple times.

\section{Prognostic factors}

The change in mouth opening between baseline and the end of the DTS exercise program was significantly less in the seven patients with a stage T4 tumor ( $p=0.044$, Mann-Whitney $U$ ). No other variables were related to change in mouth opening (Table 3).

\section{Discussion}

\section{Key results}

Mouth opening increased after the DTS exercise program. For the total study population and group $\leq 36$, this increase was significant. For group $>36$, the increase was not significant. Despite the decrease from the end of the DTS exercise program to follow-up, the increase was still significant at the follow-up appointment compared to baseline. In the patients with a stage T4 tumor, the effect of the DTS exercise program was significantly smaller. Perceived difficulty of opening the mouth improved significantly after the DTS exercise program and improved even further at follow-up, despite the decrease in mouth opening during this period. No significant effects were found in mandibular function, QoL, and overall symptomatology.

All the interviewed patients noticed effects, had positive feelings about the results, and would recommend this type of exercise therapy to other patients. Most of the patients detected a change in mouth opening because eating was easier and reported that the effects of the DTS exercise program were important. The patients reported that the DTS was easy to use. About half of the patients thought the DTS exercises were burdensome.

\section{Interpretation}

From the end of the DTS exercise program to follow-up, mouth opening decreased by $2.3 \mathrm{~mm}$ (sd 3.5). This means that about one third of the increase achieved during the DTS exercise program was lost during the follow-up period of 14 weeks. The different changes in mouth opening in group $\leq 36$ and group $>36$ were expected, and the protocol prescribed therefore was slightly different for the groups [10]. However, the DTS exercise program was actually extended for only one patient (patient P) since the other patients did not wish to continue. The non-significant increase in mouth opening in 
Table 3 Independent variables related to change in mouth opening

\begin{tabular}{|c|c|c|c|c|c|c|c|c|}
\hline & \multicolumn{4}{|c|}{ Baseline vs. end of exercises $(n=15)$} & \multicolumn{4}{|c|}{ Baseline vs. follow-up $(n=12)$} \\
\hline & $\begin{array}{l}\text { Correlation } \\
\text { coefficient }\end{array}$ & $\begin{array}{l}\text { Mean } \\
(\mathrm{sd})\end{array}$ & Significance & Test & $\begin{array}{l}\text { Correlation } \\
\text { coefficient }\end{array}$ & $\begin{array}{l}\text { Mean } \\
(\mathrm{sd})\end{array}$ & Significance & Test \\
\hline Initial mouth opening (mm) & 0.494 & & 0.061 & Spearman & -0.021 & & 0.948 & Spearman \\
\hline $\begin{array}{l}\text { Time from treatment of primary } \\
\text { tumor to start of exercises (months) }\end{array}$ & -0.085 & & 0.763 & Spearman & 0.081 & & 0.802 & Spearman \\
\hline Group & & & 0.694 & MWU & & & 1.000 & MWU \\
\hline 1 & & $7.3(4.7)$ & & & & $5.2(3.5)$ & & \\
\hline 2 & & $6.5(5.2)$ & & & & $4.5(3.1)$ & & \\
\hline Stage T4 & & & $0.044 *$ & MWU & & & 0.213 & MWU \\
\hline Yes & & $5.2(4.1)$ & & & & $7.3(2.6)$ & & \\
\hline No & & $10.7(3.7)$ & & & & $4.4(2.4)$ & & \\
\hline
\end{tabular}

Spearman Spearman's correlation coefficient, $M W U$ Mann-Whitney $U$

* Significant $(p<0.05)$

group $>36$ supports that early detection of trismus and the start of exercise therapy are important for better outcome of mouth opening [10].

Notably, following the decrease in pain at maximal mouth opening between baseline and the end of the DTS exercise program, increased pain above the level at baseline was found between the end of the DTS exercise program and follow-up. However, in the semi-structured interviews or at follow-up, none of the patients mentioned an increase of pain. We hypothesize that this might be the result of increased awareness of the situation and problems these patients have to deal with.

Mean user satisfaction assessed as D-QUEST score was 40.4 (sd 5.3), indicating that the patients scored their satisfaction with the DTS between "more or less satisfied" and "quite satisfied." Although this score does not seem to be very high, all interviewed patients reported positive feelings about the DTS exercise program.

\section{Other studies}

Effects of DTS exercises in head and neck cancer patients have been described previously in three retrospective studies; none of these reported about the follow-up of mouth opening after ending DTS exercises. In 2008, Shulman et al. evaluated 20 patients that received radiotherapy and had a mean increase in mouth opening of $13.6 \mathrm{~mm}$ (sd not known) No information regarding initial mouth opening was reported [14]. The results of that study may be an overestimate since only those patients who completed the program were analyzed (selection bias). In 2010, Stubblefield et al. reported in a preliminary report about 20 patients who received a multimodal treatment, including DTS exercises. Median improvement was $5.0 \mathrm{~mm}$ (range -4.0 to 15.0 ). Compliant patients showed greater median gain than noncompliant patients $(7.0$ (range 0-15) versus $-1.0 \mathrm{~mm}$ (range $-4.0-5.0$ ) respectively) [15]. Because of the other interventions besides the DTS exercises, the change in mouth opening cannot be attributed to the DTS only. In 2011, Baranano et al. studied 26 patients treated for trismus; mean gain in mouth opening was $6.2 \mathrm{~mm}$ (sd 3.4). In the first 6 weeks, the most gain in mouth opening was achieved [16]. The design and the results of this study are most comparable with the results of our study.

In general, the results of TheraBite ${ }^{\circledR}$ Jaw Motion Rehabilitation System ${ }^{\mathrm{TM}}$ (TheraBite) exercise therapy in literature seem similar to the results of DTS exercises, mouth opening changed between -1.9 and $13.6 \mathrm{~mm}$ [10, 22-24]. However, a head-to-head comparison between the TheraBite and DTS in a RCT has not been done. Exercise adherence regarding exercise therapy with a TheraBite was described qualitatively in 2009 [25]. It was found that motivation to exercise was based on perceived effects, self-discipline, and having a clear goal. Comparably, we found in our study that the effects of the DTS exercises and self-discipline motivated the patients.

\section{Problems and negative experiences}

One patient was not included because the mouth opening was too small $(7.0 \mathrm{~mm})$ to use a DTS. The range of motion of the DTS is 9 to $50 \mathrm{~mm}$, so patients with a mouth opening less than $9 \mathrm{~mm}$ are unable to perform DTS exercises. For exercises with other stretching devices, such as the TheraBite, a mouth opening of at least $9 \mathrm{~mm}$ is also required. Consequently, this patient could only be treated with conventional exercises.

Three patients experienced problems during or after the exercise therapy. The first patient wanted to quit after 6 weeks 
of exercising because of a decrease in mouth opening (week 0 , $21 \mathrm{~mm}$; week 4, $23 \mathrm{~mm}$; and week 6, $20 \mathrm{~mm}$ ) (patient Q). This patient had greatly increased the force adjustment of the DTS on his own volition, despite the therapist's advice to the contrary, and he did not wish to continue exercising with lowered force. The second patient had to quit after 12 weeks instead of after 16 weeks because of pain in the temporomandibular joint (contralateral to the side of the tumor) (patient $\mathrm{N}$ ). The third patient contacted us 4 weeks after ending the DTS exercise program because of a rapid decrease in mouth opening (from 46 to $32 \mathrm{~mm}$ ); conventional exercises were started and mouth opening increased again (patient $\mathrm{C}$ ).

Two patients were instructed to perform lateral exercises, but both found these lateral exercises inadequate, despite being satisfied with the range of motion exercises. Because of these findings, no analyses of active lateral exercises were performed.

About half of the patients thought the DTS exercises were burdensome. In a post hoc analysis was this burden apparently unrelated to the increase in mouth opening (median $9.0 \mathrm{~mm}$, range $5.0-13.0$, interquartile range 7.3 to 13.0 of these six patients).

\section{Clinical relevance and future perspectives}

The results of our explorative study show results of the DTS exercise program in mouth opening, pain, mandibular function, QoL, and symptomatology. Additionally, they provide insight into the patient's experiences regarding DTS exercises. This can be used in making a decision for the choice of treatment of trismus and to inform patients about the expected results. The findings need to be verified in a RCT. The results of our study can be used to determine the sample size for future studies.

\section{Strengths and limitations}

Strengths of our study are the prospective design, assessment of multiple outcome variables, assessment of the patient's experiences and compliance, and adequate follow-up after ending the DTS exercise program. The limitations are lack of blinding of the observer, the small size of the study population, lack of a control group, and missing data at the end of the DTS exercise program and follow-up.

\section{Conclusions}

Mouth opening increased $7.1 \mathrm{~mm}$ after the DTS exercise program, a significant increase relative to baseline. However, for the subgroup of patients who were treated for their cancer longer than 36 months previously, no significant increase in mouth opening was achieved.
This supports that early detection of trismus and the start of exercise therapy are important for better outcome of mouth opening. About one third of the gained increase was lost in the follow-up period. In general, the patients were satisfied about the effects and the DTS exercise program.

\section{Compliance with ethical standards}

Ethical approval All procedures performed involving human participants were in accordance with the ethical standards of the institutional and/or national research committee and with the 1964 Helsinki declaration and its later amendments or comparable ethical standards. The study was approved by the ethical review board and was carried out according to the regulations of our institute. After being given a verbal and written explanation, the patients signed the informed consent form.

Conflict of interest Dynasplint Systems Inc. Europe provided us with ten Dynasplint ${ }^{\mathbb{B}}$ Trismus Systems for the duration of the study.

\section{Appendix 1}

\section{Overview of the procedures per week}

- Baseline

- Receive instructions (oral and written) regarding the DTS exercise program and informed consent

- Measurement of mouth opening

- $\quad$ Fill in the questionnaires (MFIQ, EORTC QLQ-H\&N35, and QLQC30)

- Start DTS exercise program

- $\quad$ During the DTS exercise program

- Every 4 weeks, routine follow-up appointment, including measurement of mouth opening

- Patients can ask the therapist questions about the DTS exercises and stretching forces

- End of DTS exercise program

- $\quad$ Stop DTS exercises

- Measurement of mouth opening

- $\quad$ Fill in the questionnaires (MFIQ, EORTC QLQ-C30, and QLQH\&N35, and D-QUEST 2.0)

- Qualitative research by means of a semi-structured interview to analyze experiences, comfort, and compliance

- Follow-up (14 weeks after ending the DTS exercise program)

- Measurement of mouth opening

- Fill in the questionnaires (MFIQ, EORTC QLQ-C30, and QLQ-H\&N35) 


\section{Appendix 2}

\section{Topics addressed during the semi-structured interview}

- -Experiences

1. How did you experience exercising with the DTS?

2. Did you previously exercise with other stretching devices and what was your experience? Which device do you prefer and why?

3. What are the effects of the DTS exercise program?

4. How important are these effects for you?

5. How did you detect change in mouth opening?

6. Have you experienced changes in the functioning of your mouth? During:

(a) Social activities

(b) Speaking, including understandability

(c) Eating, including less food dropping from cutlery

(d) Drinking

(e) Laughing

(f) Yawning

(g) Swallowing

(h) Pain

(i) Biting

(j) Chewing

7. What benefits of the DTS exercise program have you experienced?

8. What adverse effects of the DTS exercise program have you experienced?

9. How did your diet change since the DTS exercise program?

10. What do you think of the results of the DTS exercise program?

11. Would you recommend the DTS exercise program to other patients?

12. What suggestions do you have to improve exercise therapy with a DTS?

- Comfort (stretching forces)

13. How did you experience the forces applied by the DTS on the jaws while exercising?

14. How did you experience operating the DTS?

15. How did you experience adjusting the correct stretching forces?

16. What problems arose during the DTS exercises?

17. How did you cope with pain during stretching?

18. What is the optimal stretching time for you?

19. What happened to your jaw during stretching and what did you feel?

- Compliance

20. What do you think about exercising regularly according to your protocol prescribed?
21. What do you think about keeping the exercise diary?

22. How often did you exercise?

23. Which factors motivated you to follow the exercise protocol?

24. What difficulties did you experience in following the exercise protocol?

25. Were you able to exercise regularly according to the protocol? If not, did you follow your own schedule?

\section{Appendix 3}

Table 4 Active lateral exercises

\begin{tabular}{llll}
\hline & $\begin{array}{l}\text { Baseline } \\
(n=18)\end{array}$ & $\begin{array}{l}\text { End of DTS } \\
\text { exercise program } \\
(n=15)\end{array}$ & $\begin{array}{l}\text { Follow-up } \\
(n=12)\end{array}$ \\
Mean (sd) & Mean (sd) & Mean (sd) \\
\hline $\begin{array}{c}\text { Left active lateral } \\
\text { exercises of the } \\
\text { mandible (mm) }\end{array}$ & $5.4(3.0)$ & $6.4(3.0)$ & $6.8(3.5)$ \\
$\begin{array}{c}\text { Right active lateral } \\
\text { exercises of the } \\
\text { mandible }(\mathrm{mm})\end{array}$ & $4.4(2.7)$ & $5.5(3.3)$ & $5.5(3.1)$ \\
\hline
\end{tabular}

Open Access This article is distributed under the terms of the Creative Commons Attribution-NonCommercial 4.0 International License (http:// creativecommons.org/licenses/by-nc/4.0/), which permits any noncommercial use, distribution, and reproduction in any medium, provided you give appropriate credit to the original author(s) and the source, provide a link to the Creative Commons license, and indicate if changes were made.

\section{References}

1. Scott B, Butterworth C, Lowe D, Rogers SN (2008) Factors associated with restricted mouth opening and its relationship to health-related quality of life in patients attending a maxillofacial oncology clinic. Oral Oncol 44:430-438

2. Dijkstra PU, Huisman PM, Roodenburg JL (2006) Criteria for trismus in head and neck oncology. Int J Oral Maxillofac Surg 35:337-342

3. van der Molen L, van Rossum MA, Ackerstaff AH, Smeele LE, Rasch CR, Hilgers FJ (2009) Pretreatment organ function in patients with advanced head and neck cancer: clinical outcome measures and patients' views. BMC Ear Nose Throat Disord 9:10

4. Johnson J, van As-Brooks CJ, Fagerberg-Mohlin B, Finizia C (2010) Trismus in head and neck cancer patients in Sweden: incidence and risk factors. Med Sci Monit 16:CR278-CR282

5. Bensadoun RJ, Riesenbeck D, Lockhart PB, Elting LS, Spijkervet FK, Brennan MT, Trismus Section, Oral Care Study Group, Multinational Association for Supportive Care in Cancer (MASCC)/International Society of Oral Oncology (ISOO) (2010) A systematic review of trismus induced by cancer therapies in head and neck cancer patients. Support Care Cancer 18:1033-1038

6. Louise Kent M, Brennan MT, Noll JL, Fox PC, Burri SH, Hunter JC, Lockhart PB (2008) Radiation-induced trismus in head and neck cancer patients. Support Care Cancer 16:305-309 
7. Weber C, Dommerich S, Pau HW, Kramp B (2010) Limited mouth opening after primary therapy of head and neck cancer. Oral Maxillofac Surg 14:169-173

8. Vissink A, Jansma J, Spijkervet FK, Burlage FR, Coppes RP (2003) Oral sequelae of head and neck radiotherapy. Crit Rev Oral Biol Med 14:199-212

9. Dijkstra PU, Kalk WW, Roodenburg JL (2004) Trismus in head and neck oncology: a systematic review. Oral Oncol 40:879-889

10. Kamstra JI, Roodenburg JL, Beurskens CH, Reintsema H, Dijkstra PU (2013) TheraBite exercises to treat trismus secondary to head and neck cancer. Support Care Cancer 21: 951-957

11. Fischer DJ, Epstein JB (2008) Management of patients who have undergone head and neck cancer therapy. Dent Clin North Am 52: $39-60$ viii

12. Bhatia KS, King AD, Paunipagar BK, Abrigo J, Vlantis AC, Leung SF, Ahuja AT (2009) MRI findings in patients with severe trismus following radiotherapy for nasopharyngeal carcinoma. Eur Radiol 19:2586-2593

13. Usuba M, Akai M, Shirasaki Y, Miyakawa S (2007) Experimental joint contracture correction with low torquelong duration repeated stretching. Clin Orthop Relat Res 456:70-78

14. Shulman DH, Shipman B, Willis FB (2008) Treating trismus with dynamic splinting: a cohort, case series. Adv Ther 25: $9-16$

15. Stubblefield MD, Manfield L, Riedel ER (2010) A preliminary report on the efficacy of a dynamic jaw opening device (dynasplint trismus system) as part of the multimodal treatment of trismus in patients with head and neck cancer. Arch Phys Med Rehabil 91:1278-1282

16. Baranano CF, Rosenthal EL, Morgan BA, McColloch NL, Magnuson JS (2011) Dynasplint for the management of trismus after treatment of upper aerodigestive tract cancer: a retrospective study. Ear Nose Throat J 90:584-590

17. Stegenga B, de Bont LG, de Leeuw R, Boering G (1993) Assessment of mandibular function impairment associated with temporomandibular joint osteoarthrosis and internal derangement. J Orofac Pain 7:183-195
18. Bjordal K, de Graeff A, Fayers PM, Hammerlid E, van Pottelsberghe C, Curran D, Ahlner-Elmqvist M, Maher EJ, Meyza JW, Bredart A, Soderholm AL, Arraras JJ, Feine JS, Abendstein H, Morton RP, Pignon T, Huguenin P, Bottomly A, Kaasa S (2000) A 12 country field study of the EORTC QLQ-C30 (version 3.0) and the head and neck cancer specific module (EORTC QLQ-H\&N35) in head and neck patients. EORTC Quality of Life Group. Eur J Cancer 36: 1796-1807

19. Bjordal K, Hammerlid E, Ahlner-Elmqvist M, de Graeff A, Boysen M, Evensen JF, Biorklund A, de Leeuw JR, Fayers PM, Jannert M, Westin T, Kaasa S (1999) Quality of life in head and neck cancer patients: validation of the European Organization for Research and Treatment of Cancer Quality of Life Questionnaire-H\&N35. J Clin Oncol 17:1008-1019

20. Singer S, Wollbruck D, Wulke C, Dietz A, Klemm E, Oeken J, Meister EF, Gudziol H, Bindewald J, Schwarz R (2009) Validation of the EORTC QLQ-C30 and EORTC QLQ$\mathrm{H} \& \mathrm{~N} 35$ in patients with laryngeal cancer after surgery. Head Neck 31:64-76

21. Wessels RD, De Witte LP (2003) Reliability and validity of the Dutch version of QUEST 2.0 with users of various types of assistive devices. Disabil Rehabil 25:267-272

22. Buchbinder D, Currivan RB, Kaplan AJ, Urken ML (1993) Mobilization regimens for the prevention of jaw hypomobility in the radiated patient: a comparison of three techniques. J Oral Maxillofac Surg 51:863-867

23. Pauli N, Fagerberg-Mohlin B, Andrell P, Finizia C (2014) Exercise intervention for the treatment of trismus in head and neck cancer. Acta Oncol 53:502-509

24. Tang Y, Shen Q, Wang Y, Lu K, Wang Y, Peng Y (2011) A randomized prospective study of rehabilitation therapy in the treatment of radiation-induced dysphagia and trismus. Strahlenther Onkol 187:39-44

25. Melchers LJ, Van Weert E, Beurskens CH, Reintsema H, Slagter AP, Roodenburg JL, Dijkstra PU (2009) Exercise adherence in patients with trismus due to head and neck oncology: a qualitative study into the use of the Therabite. Int J Oral Maxillofac Surg 38: 947-954 